\title{
A Rare Case of Urethral Fibroid
}

Medikonda Jayalakshmi ${ }^{1}$, Rotte Subbarao², Penmetsa Poornima ${ }^{3}$, Palavalasa Srujana ${ }^{4}$, Nakkina Manasa ${ }^{5}$, Gali Himabindu 6

${ }^{1}$ Department of Obstetrics and Gynaecology, Maharaja's Institute of Medial Sciences, Vizianagaram, Andhra Pradesh, India. ${ }^{2}$ Department of Obstetrics and Gynaecology, Maharaja's Institute of Medial Sciences,

Vizianagaram, Andhra Pradesh, India. ${ }^{3}$ Department of Obstetrics and Gynaecology, Maharaja's Institute of Medial Sciences, Vizianagaram, Andhra Pradesh, India. ${ }^{4}$ Department of Obstetrics and Gynaecology, Maharaja's Institute of Medial Sciences, Vizianagaram, Andhra Pradesh, India. ${ }^{5}$ Department of Obstetrics and Gynaecology, Maharaja's Institute of Medial Sciences, Vizianagaram, Andhra Pradesh, India. ${ }^{6}$ Department of Obstetrics and Gynaecology, Maharaja's Institute of Medial Sciences, Vizianagaram, Andhra Pradesh, India.

\section{INTRODUCTION}

Leiomyomas are benign mesenchymal tumours that arise from the smooth muscle, mostly located in genital tract. M/C site of leiomyoma is uterus. (1) Leiomyoma arising from urethra are rare. Leiomyomas are most commonly seen in uterus. (2) Extra uterine leiomyomas are usually seen arising from vulva, ovaries, urethra, urinary bladder, GIT, and Vagina. (3) Leiomyoma of urethra is a rare benign mesenchymal tumor that affects women more often than men. Usually located in proximal urethra, seen in reproductive age group (mean age 41 yrs.) with possible hormone dependence. Presents with a variety of symptoms include - UTI, urinary retention, mass per urethra, dysuria. Diagnosis is by USG, MRI (4) confirmed by HPE. Complete surgical excision is the treatment of choice, recurrence is rare.

\section{PRESENTATION OF CASE}

A 40-year-old female from Vizianagaram presented to gynaec OPD with complaints of mass per vagina since 6-months, difficulty in micturition since 6 months, and heavy menstrual bleeding since 3 months - changing 6 pads/day, no clots, no pain. Previous menstrual history $-3 / 30$ day, regular, no clots, no pain. Age at menarche- 13 years. Obstetric history - $\mathrm{P}_{3} \mathrm{~L}_{3}$, LCB -16 years, full term home deliveries, tubectomised. On examination- Pallor + , PR -80 / min, B.P.- 120/80 mmHg. Thyroid, breast and spine - no abnormality detected. On per abdomen examination, suprapubic mass of size 14 weeks was felt which was freely mobile from side to side and was firm in consistency. A mass of size $8 \times 5 \mathrm{cms}$ was noted arising from posterior urethral wall extending onto anterior vaginal wall. Mass could be palpated $2 \mathrm{~cm}$ from introitus, extending into anterior vaginal wall. An irregular shaped ulcer was noted over posterior aspect of mass. It was firm in consistency, non-tender, not bleeding on touch, irreducible. Urethral meatus was visible above the mass. Cervix could not be visualized on per speculum examination. Per vaginum - uterus was irregularly enlarged to 14 weeks size, mobile, fornices free, cervical movements were transmitted to the mass. Anterior vaginal mass was separate from cervix.

\section{CLINICAL DIAGNOSIS}

Fibroid uterus with ? Urethral fibroid.

\section{DIFFERENTIAL DIAGNOSIS}

Urethral Diverticulum, Caruncle, Urethral Polyp, Gartner's Duct Cyst, Vaginal Fibroid, Bartholin Cyst, Urethral Carcinoma.
Corresponding Author: Dr. Gali Himabindu, Flat No. 201, Sathvikanadha Residency, Otugutta, Venugopala Puram, Vizianagaram-535003, Andhra Pradesh, India.

E-mail: bindu.gali@gmail.com

DOI: 10.14260/jemds/2020/85

Financial or Other Competing Interests: None.

How to Cite This Article: Jayalakshmi M, Subbarao R, Poornima P, et al. A rare case of urethral fibroid. J. Evolution Med. Dent. Sci. 2020;9 (06):372373, DOI: $10.14260 /$ jemds/2020/85

Submission 19-11-2019, Peer Review 16-01-2020, Acceptance 22-01-2020, Published 10-02-2020.

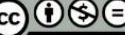



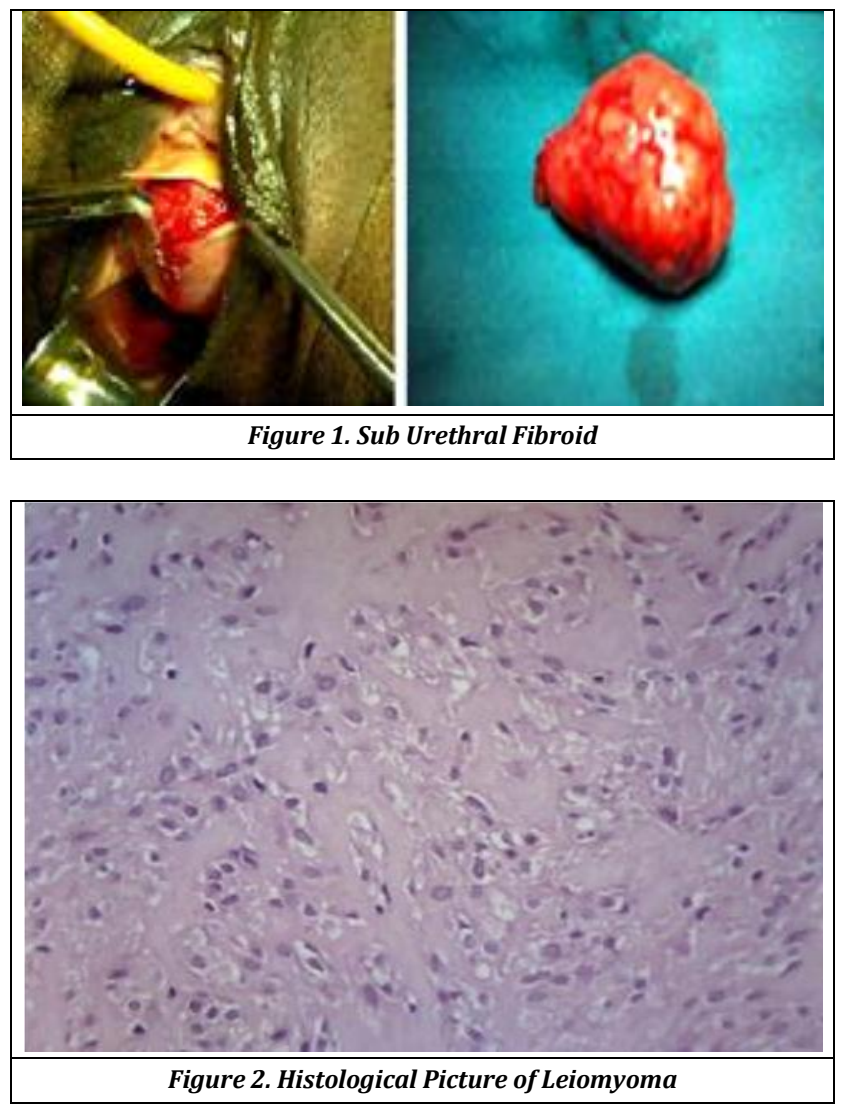

On imaging (USG/MRI) diagnosis of urethral fibroid was confirmed, with multiple fibroids in uterus. Routine blood investigations were with in normal limits except for anaemia. Diagnosis was confirmed by HPE.

\section{DISCUSSION OF MANAGEMENT}

TAH + Excision of Urethral Fibroid (Vaginal Approach). Postop period was uneventful. Patient was discharged on $6^{\text {th }}$ day \& was on regular follow up with no recurrence.

\section{REFERENCES}

[1] Wein AJ, Kavoussi LR, Partin AW, et al. Campbell-Walsh text book of Urology. Chap - 38. Vol. 1. 11 th edn. Elsevier 2016: p. 879.

[2] Ju UC, Kim YH, Kim JW, et al. A case of suburethral myoma of the vagina in pregnancy. Korean J Obstet Gynaecol 2011;54 (3):159-62.

[3] Adducci J. Leiomyoma of the anterior vagina wall in suburethral location causing stress incontinence: report of a case. J Urol 1965;93 (2):255-7.

[4] Al Hilli MM, Stewart EA. Magnetic resonance- guided focussed ultrasound surgery. Seminar Reproductive Medicine 2010:28 (3):242-9.

[5] Cramer SF, Mann L, Calianese E, et al. Association of seedling myomas with myometrial hyperplasia. Hum Pathol 2009;40 (2):218-25. 